\title{
Solid Particle Erosion Models and their Application to Predict Wear in Pelton Turbine Injector
}

\author{
Tri Ratna Bajracharya ${ }^{1,2}$, Rajendra Shrestha ${ }^{1,2}$, Ashesh Babu Timilsina ${ }^{1,2, *}$ \\ ${ }^{I}$ Department of Mechanical Engineering, Pulchowk Campus, Institute of Engineering, Tribhuvan University \\ ${ }^{2}$ Center for Energy Studies, Institute of Engineering, Tribhuvan University \\ Corresponding Email: abtimilsina@pcampus.edu.np
}

\begin{abstract}
:
Analysis of water quality of Himalayan originated rivers reveals the heavy sediment loading with a major portion of the sediment being hard mineral, quartz. Despite the incorporation of desanders to reduce the sediment content passing through hydro mechanical parts, significant wear is being reported in south-Asian hydroelectric projects. Repeated impact of such solid particles which are harder than the material of mechanical parts (mostly steel) is known to cause the erosion. Flow parameters, impact angle, mechanical properties of wall and particle, particle shape and size are commonly explored variables that affect the erosion of solid by the sedimentladen flow. In order to predict such erosion, starting with Finnie erosion model, several other erosion models considering aforementioned variables are proposed but are mostly case dependent. Application of numerical methods to understand flow problems constitutes the field of Computational Fluid Dynamics (CFD). Due to enclosed flow, reactions turbines took accelerated development in the investigations by CFD modeling. However, free surface jet and complex flow mechanism in buckets have been a major barrier to the application of CFD in case of Pelton turbines. Recent advancements in computational techniques, technological advancements have enabled to investigate flow in Pelton turbine by CFD. However, it is least understood which among the proposed erosion models will predict erosion occurring in Pelton turbine and assembly. This article explores about erosion in Pelton turbine, various erosion models and state of the art in modeling erosion of Pelton turbine injector. It is discussed which among the erosion models shall best predict the erosion occurring in the Pelton turbine injector. A short list of erosion models is then given which can be applied for the case of erosion in Pelton turbine injectors.
\end{abstract}

Keywords: Pelton Turbine, Erosion Modeling, Needle Erosion, CFD based Erosion Modeling

\section{Introduction}

Higher sediment concentration with the domination of hard minerals such as quartz and feldspar are seen in Himalayan originating rivers $[1,2]$. Despite the incorporation of desilting/desanding arrangements, sand particles pass through the water conveying system thus have caused severe erosion damage to hydro-mechanical parts of hydroelectric power generating projects. These eroded parts then need to be repaired/replaced thus adding up the maintenance cost [3]. Despite added maintenance costs, the generating company also has to bear production losses thus the erosion of hydraulic machinery is an economically important issue [4]. In addition to financial losses, other effects of erosion are the loss of efficiency, failure of components. It can be understood that beforehand prediction of such failures due to eroded parts will help engineers to predict the optimal repair time thus preventing damages, hazards and ensure operational safety of hydropower projects.
In addition to financial losses, other effects of erosion are the loss of efficiency, failure of components. Despite heavy investment on the research and development to understand erosion and its prevention techniques, the erosion phenomenon is yet not clearly understood. Study of review papers $[1,5,6]$ suggests that different researchers have proposed a different model to predict the solid particle erosion.

Selection of hydro turbine for a particular site depends upon the head and flow conditions $[7,8]$. Figure 1 shows the application ranges of various types of hydraulic turbines. It can be seen that Pelton turbine is employed in high head sites. Being high head turbine, Pelton turbine mostly employed in the mountainous area.

The main objective of this paper is to briefly introduce erosion of Pelton turbine injector, solid particle erosion models and their application to predict erosion in Pelton turbine needle using Computational Fluid Dynamics (CFD). A better understanding of erosion phenomenon, formulation of models to predict the occurrence of such 
phenomenon, a methodology for verification and validation is required to before we attempt to predict and analyze erosion. Subsequent sections will present about basic theory of solid particle erosion, fundamentals of erosion models, methodology for CFD based erosion modelling and attempts made so far to predict erosion in Pelton turbine needle.

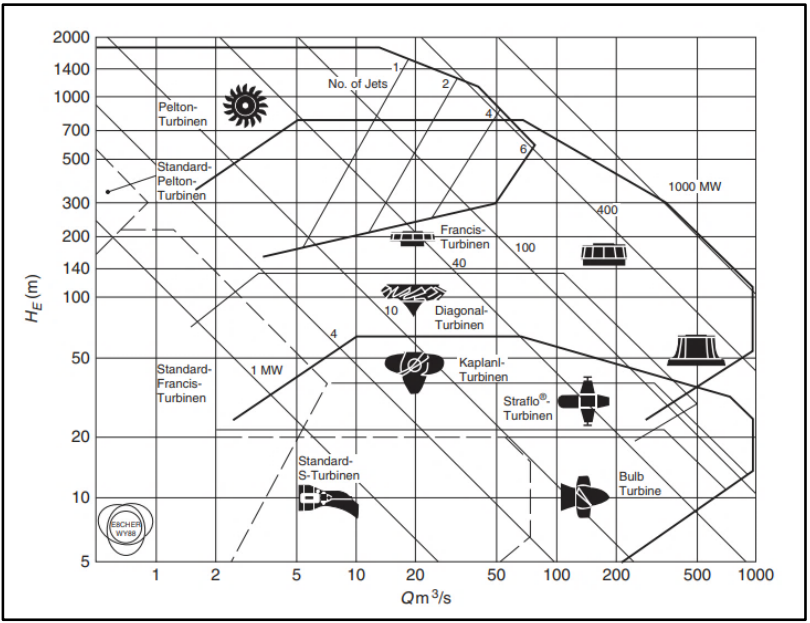

Figure 1: Turbine Selection Nomogram

\section{Theory of Solid Particle Erosion}

In the fluid conveying system, if the fluid is a carrier of solid particles, these particles erode the wall material of pipe hosting the fluid flow by series of impacts which is commonly understood in tribology as solid particle erosion [9].

The mechanism of erosive wear has been reviewed in [5,11] and more recently in [10] and [6]. Parsi et al. 2014 [6], has reviewed about the solid particle erosion modeling for oil and gas industries and Javaheri et al. 2018 [10], has reviewed about the slurry (a heterogeneous mixture of a fluid, and one or more kinds of solid particles varying in size) erosion of steel and classified the parameters involved into four categories as shown in figure 2 .

\subsection{Slurry Characteristics}

The characteristics of a slurry are defined by amount of solid per unit amount of fluid (slurry concentration), aggressiveness of fluid towards corroding the wall material (Corrosivity), the resistance of slurry towards flow (viscosity), the degree of hotness (temperature) and the flow pattern (turbulence).

\subsection{Target Material Properties}

In erosion studies, the solid region where erosion occurs (or is studied) is named as target or target wall. The

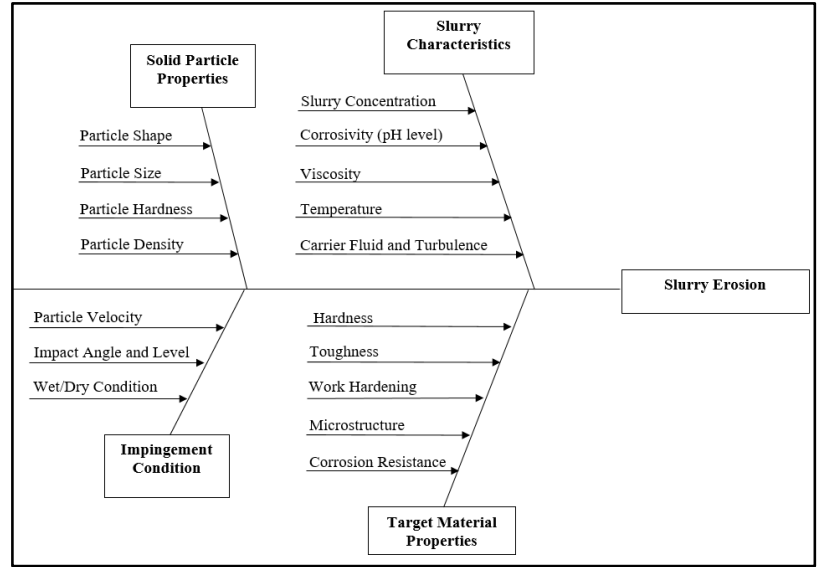

Figure 2: Parameters affecting Solid Particle Erosion, Adapted from [10]

mechanical properties of the target material are also a key factor that determines the erosion and its nature. As previously discussed, the mechanism of erosion is different in different materials that can be predicted/ determined form the material properties. Thus, considerations of mechanical properties of target material before evaluating the solid particle erosion is very important. The measure of the resistance to plastic deformation (Hardness), capacity to absorb impact energy without deformation (toughness), internal molecular arrangement of material (microstructure), change in hardness of material due to series of impact (work hardening), resistance to oxidation and chemical resistance (Corrosion Resistance) are indicated as key mechanical properties that must be paid attention to.

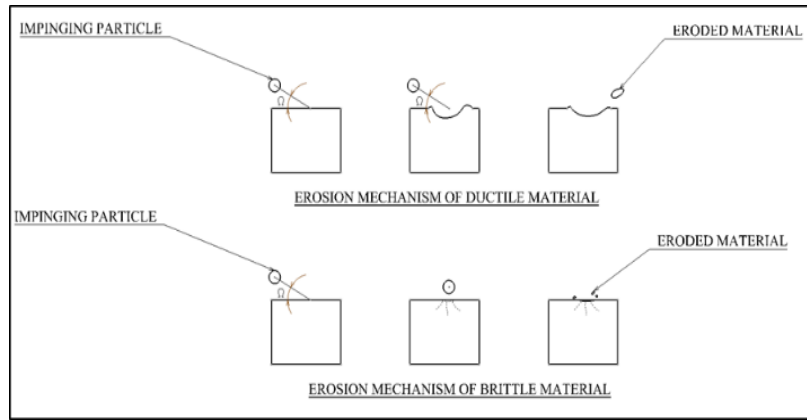

Figure 3: Erosion Mechanism for Brittle and Ductile Materials

The literature survey done by several authors reveals different erosion mechanism for ductile and brittle materials. While there is wide acceptance of erosion mechanism for the brittle materials while different mechanism is proposed for erosion mechanism of ductile materials. Figure 3 shows the schematic of erosion mechanism for these materials. Many researchers agree that ductile materials erode by the creation of crater and material deposition on either side of the crater which later 
separates from the parent body. The brittle material, on the other hand, erodes by the radial crack formation in the vicinity of the impact point.

\subsection{Solid Particle Properties}

The particle shape and size (measured as mean diameter of the particle), hardness and density (mass per unit volume) of material that forms the particle significantly influence the erosion. Most commonly, the solid particle properties are studied as following:

1. Sediment Size Distribution

2. Mineral Composition

3. Sediment Shape

\subsubsection{Sediment Size Distribution}

The Particle Size Distribution (PSD) of grains or solid suspended in fluid media (slurry) refers to the list of range of particle size and their quantity in the given sample. The PSD of any slurry is of particular importance to understand its physical and chemical properties. It can be known from above-discussed literature that, presence of solid sediments in fluid is a leading cause of solid particle erosion. The change in concentration of solid particles affects the efficiency of hydraulic turbines and its erosion [12]. Different approaches are generally adopted to minimize the slurry concentration and reduce sediment size downstream.

Sieve Analysis is a generally adopted method for analysis of PSD. In this method, sieves of different mesh size are used to separate particles of different size. The result is obtained in a form of range analysis. This method is widely accepted and is one of the most preferred method because of its simplicity, cheapness and ease in data interpretation. Graphical presentation of the distribution is then done, which is commonly understood as PSD curve by application of Rosin Rammler fitting.

Rosin and Rammler in 1933 [13] developed method to reproduce the PSD as a continuous function by use of following equation:

$$
Y=1-\exp \left(-\frac{x}{x_{0}}\right)^{n}
$$

Where,

$Y=$ cumulative fraction of material by weight less than size $\mathrm{x}, n=$ a constant describing material uniformity, and $x_{0}=$ the characteristic particle size, defined as the size at which $63.2 \%\left(1-\frac{1}{e}=0.632\right)$ of the particles (by weight) are smaller
The uniformity constant $\mathrm{n}$ is the slope of the line $\ln \left(\frac{1}{1-Y}\right)$ versus $\mathrm{x}$ on $\log -\log$ coordinates.

\subsubsection{Mineral Composition}

Mineral composition of the sample defines the concentration by mass of various minerals in the solid particle (sediment) sample. It is well understood that mineral composition of sediment alters the erosion potential of the sediment [14]. Different minerals have different hardness [14-16] and different shape [2]. Minerals that are harder (measured on Moh's hardness scale) have higher potential to cause solid particle erosion. Turbine materials have hardness of 6 to 6.5 on Moh's scale [14]. Sediment sample analysis of hydropower plant [14] or to be built hydropower projects [16] reveal that major portion of the sediment is quartz which have hardness of 7 on Moh's scale and is most abundantly present mineral in sediment sample $(>70 \%)$. This hardness differential further accelerates the erosion potential of the sediment sample.

\subsubsection{Particle Shape}

There are many parameters used when quantifying the shape of a particles, such as size, form, flatness, sphericity, elongation, and roundness. Microscopic analysis and digital image processing are generally used to reproduce the sediment shape. Sediment shape characterization is very difficult and time-consuming task.

\section{$2.4 \quad$ Impingement Conditions}

The particle impingement condition constitutes the particle velocity, impact angle ( $\Omega$ in figure 3 ), erosion per impact (impact level), the condition of injection of a particle (wet or dry) and the particle velocity.

Extensive discussion of the effect of these variables with erosion rate is discussed in [1] and more recently by [2]. In following section, except for where indicated, the symbols used are as used by [6].

\section{Erosion Models}

Erosion phenomenon is studied experimentally or theoretically. While experimental studies formulate empirical relations, theoretical studies deduce mathematical expression to describe erosion in form of mass lost per unit mass of particles (erosion ratio) or mass lost as the function of time. The theoretical models are deduced by energy balance for particle-target wall collision or by dimensional analysis. Finnie 1960 [3], earlier proposed a mathematical model to quantitatively 
predict erosion by classifying the material as brittle and ductile. With some assumptions, and proposing that ductile materials erode by plastic deformation and brittle ones erode by radial cracks formation, he proposed following equations to predict the volume of target material removed by single abrasive grain.

$$
\begin{gathered}
\varepsilon_{V P}=\frac{m_{p} V_{p}^{2}}{P \varphi_{k}}\left(\sin (2 \alpha)-\frac{6}{k} \sin ^{2}(\alpha)\right) \text { for } \tan (\alpha) \leq \frac{k}{6} \\
\varepsilon_{V P}=\frac{m_{p} V_{p}^{2}}{P \varphi_{k}}\left(\frac{k}{6} \cos ^{2}(\alpha)\right) \text { for } \tan (\alpha) \geq \frac{k}{6}
\end{gathered}
$$

Bitter then in 1963 proposed erosion occurs due to two different mechanisms, repeated deformation and cutting. In [4] the erosion due to repeated deformation is described and in [5], erosion due to cutting wear is described. The summation (or superposition) of erosion predicted by two mechanisms gives the total erosion of the target wall.

Erosion due to deformation,

$$
\varepsilon_{V P}=\frac{1 M\left(V_{p} \sin \alpha-K\right)^{2}}{2 \delta}
$$

Erosion due to cutting,

$$
\begin{gathered}
\varepsilon_{V C}=\frac{2 M V_{p}\left(V_{p} \sin \alpha-K\right)^{2}}{\left(V_{p} \sin \alpha\right)^{\frac{1}{2}}}\left\{V_{p} \cos \alpha-\frac{C\left(V_{p} \sin \alpha-K\right)^{2}}{\left(V_{p} \sin \alpha\right)^{\frac{1}{2}}} \chi\right\} \\
\text { for } \alpha \geq \alpha_{P 0} \\
\varepsilon_{V C}=\frac{\frac{1}{2} M\left[V_{p}^{2} \cos ^{2}(\alpha)-K_{1}\left(V_{p} \sin \alpha-K\right)^{\frac{3}{2}}\right]}{\chi} \text { for } \alpha \leq \alpha_{P 0}
\end{gathered}
$$

Erosion due to cutting is derived by considering particles having zero horizontal component of velocity and a nonzero horizontal component of velocity after collision.

Proposing that the parallel component of velocity of the particle is responsible for cutting wear and the normal component is responsible for deformation wear, in [17] two equations were then proposed for prediction of wear for large and small angles of attack.

$$
\begin{gathered}
\varepsilon_{V}=\frac{\frac{1}{2} M\left[V_{p}^{2} \cos ^{2}(\alpha)-\left(V_{r}\right)^{2}\right]}{\chi}+\frac{\frac{1}{2} M\left[\left(V_{p} \sin \alpha-K\right)^{2}\right]}{\delta} \\
\text { for } \alpha<\alpha_{P 0} \\
\varepsilon_{V}=\frac{\frac{1}{2} M\left[V_{p}^{2} \cos ^{2}(\alpha)\right]}{\chi}+\frac{\frac{1}{2} M\left[\left(V_{p} \sin \alpha-K\right)^{2}\right]}{\delta} \text { for } \alpha>\alpha_{P 0}
\end{gathered}
$$

The first term in the above equation gives erosion due to cutting while the second term is for erosion due to deformation.

Finnie later modified the erosion model proposed in [3] and is published in [6]. However, the limitation of the previous model to predict erosion for normal impact angle still remained. Many other researchers published erosion models for prediction of erosion due to single particle and mostly on similar assumptions of velocity component, impact angle with erosion mechanisms as proposed by [17].

Tilly [18] studied experimentally the erosion mechanism of erosion in ductile materials and suggested that erosion of ductile materials occurs in two stages. At first, the particle strikes the surface producing an indentation and deposition of the material at the side of the indentation. Then after the deposition detaches from the parent body and fragments are projected radially from the primary site. Tilly then proposed two-stage erosion and final erosion model as superposition of primary and secondary erosion.

Jennings et al. [19] also experimentally studied the erosion phenomenon in ductile materials and proposed that melting of the target material due is the cause of erosion. Dimensional analysis was then employed to develop the mathematical model for predicting the erosion of ductile materials. Hutchings 1976 [9], experimentally studied erosion in mild steel using steel spheres. The model proposed is modified in a series of experiments performed thereafter. The assumptions made by Hutchings in further development was neglecting the particle-particle interaction and integrity of particle after the collision. Hutching's model is also widely accepted as the fatigue model.

Sundararajan [20] developed erosion model to predict erosion rate for ductile materials for all impact angles and different particle shape. The concept of plastic deformation due to the impact of the particle forming lip around the point of impact was used to develop mathematical model. Single equation was then proposed for evaluating the dimensionless erosion as totality of erosion caused due to normal impact of the particle and the oblique impact. At the Erosion/Corrosion Research Center (E/CRC) erosion is being studied by performing both experiments and modeling. The experiments are a combination of direct impingement tests and tests performed in flow loops. The direct impingement tests are used to determine the erosivity of a variety of materials. A series of erosion models are thus being proposed by the research center based on the direct impingement tests. The model incorporates direct relation of the erosion with the velocity of particle, angle of erosion. McLaury [21] proposed a model for predicting the erosion rate of sand particles in water. The model has primarily been used to simulate erosion rates in slurry erosion. The McLaury erosion rate is determined by

$$
E=A V^{n} f(\gamma) ; A=F B h^{k}
$$


Where, $\mathrm{F}=$ Empirical Constant, $\mathrm{V}=$ Particle impact velocity, $\mathrm{Bh}=$ Brinell's hardness number of wall material, $\mathrm{k}$ is a constant that depends on material composing wall.

Oka et al. in [22] and [23] proposed erosion model based on erosion occurring during normal impact angle, and considering the mechanical properties of both the target material and the particle material. The final form of model often known as Oka erosion model is described as:

Erosion occurring at normal impact angle,

$$
\varepsilon_{90}=K_{p}\left(k_{4} H_{v}\right)^{k_{1} b}\left(\frac{V_{p}}{v^{\prime}}\right)^{k_{2}}\left(\frac{d_{p}}{d^{\prime}}\right)^{k_{3}}
$$

Erosion occuring at any impact angle, $\varepsilon_{\alpha}=f(\alpha) \varepsilon_{90}$

In above equation, $\mathrm{K}, \mathrm{k}_{1}, \mathrm{k}_{2}, \mathrm{k}_{3}$ are constants depending on material properties and particle properties.

In fluent generic model [17] particle erosion and accretion rates can be monitored at wall boundaries. The erosion rate is defined as

$$
R_{\text {erosion }}=\sum_{p=1}^{N_{\text {particles }}} \frac{\dot{m}_{p} C\left(d_{p}\right) f(\gamma) v^{b(v)}}{A_{\text {face }}}
$$

Where $C\left(d_{p}\right)$ is a function of particle diameter, and $f(\gamma)$ is a dimensionless function of the impact angle $\gamma, v$ is the relative particle velocity, $b(v)$ is a function of relative particle velocity and $A_{\text {face }}$ is the area of the cell face at the wall.

The erosion rate as computed is displayed in units of removed material/(area-time), that is mass flux, and can, therefore, be changed accordingly to the defined units in ANSYS Fluent [24]. More importantly, by simple simplifications of aforementioned erosion we can deduce the model in form of generic erosion model and thus be used in fluent. An example of such simplification is provided in ANSYS Fluent User Guide 17.0.

Det Norske Veritas (DNV) devised guideline on how to assess erosion based on CFD data and experimental data. DNV RP 0501 (2015) provides guidelines for managing sand production and calculation of erosion. The guidelines however don't include the process to calculate erosion occurring in Nozzle.

Similarly, other models are also proposed verified with solid particle erosion data but only few of them are verified experimentally for sand erosion.

\section{State of the Art in Modeling Erosion in Pelton Turbine Needle}

Pelton turbine needle (or spear) is an assembled component in the nozzle and its erosion is being studied globally experimentally as well as by CFD simulations.

\subsection{Flow and Sediment erosion in Pelton Turbine}

\subsubsection{Erosion Classification}

Broadly speaking, the erosion due to sand particles in hydro turbines are due to following causes [25].

1. Turbulence erosion: Erosion due to high turbulence in the boundary layers

2. Accelerated flow: Due to flow acceleration, particles are separated from flow and collide with the walls.

3. Vortex erosion: Formation of vortices due course of flow will trap particles within it thus causing erosion in region of vortex formation due to repeated impact on the wall.

In turbine erosion, literatures [25] classify the erosion as following which has been widely accepted and republished in [26,27]:

1. Metallic luster - A shining surface with no traces of paint, scale or rust.

2. Fine-scale erosion - A surface with rare, separately located and skin-deep scales.

3. Scaly erosion - A surface entirely covered with skindeep fine scales.

4. Large-sized scaly erosion - A surface entirely covered with fishy scales.

5. In-depth erosion - A surface covered with deep and long channels.

6. Through holes or entire metal wear out.

\subsubsection{Flow and Erosion Areas}

Among the turbine components, the first one to interact with the sediment-laden water is the injector which thus suffers from erosion wear. Figure 2.5 shows typical erosion in Pelton turbine. The direct effect of the erosion is change in shape of the nozzle and needle thus altering the value of coefficient $k$ in equation 2.2. This erosion may affect the jet quality thus its energy content.

Hence, it is very relevant to study about the effect of eroded needle/nozzle on the jet shape. Review of erosion in Pelton turbine parts has been provided in many literatures $[12,15,27,28]$.

The early investigations of flow in Pelton turbine were based on experiments of very least publication can be found. Nonoshita et al. [29], first published about the 


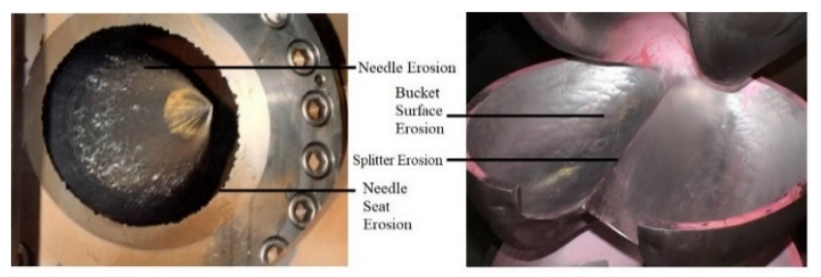

Figure 4: Typical erosion in Pelton turbine parts (left: Mel Norway [27]; right: Bucket of Khimti Powerplant, Nepal [12])

numerical simulation of the Pelton turbine jet. The authors have assumed an axisymmetric jet for the purpose of numerical simulation and have shown the effect of needle stroke and head on the velocity distribution.

In the experimental studies of jet by photographic images, the photographic images of the jet for different nozzle opening are revealed [30]. It can be seen from the images that the jet diameter decreases along with the decrease in nozzle opening. On partially opened condition of the needle, the jet follows the needle contour as explained by the Coanda effect. Furthermore, there is significant decrease in jet diameter in nozzle opening less than $50 \%$. Additional investigation of the jet shape and flow of the Pelton turbine jet with experimental approach by using Laser Doppler Anemometry (LDA) method done further validates the jet contraction and expansion phenomenon [31].

The first dedicated study about sediment erosion in Pelton turbine needle is a case study of a hydropower plant in Nepal [15]. Before this, dedicated study to understand about erosion in Pelton turbine nozzle has been least published. In the study, erosion in Pelton turbine needle is studied by field observations and erosion-prone area in the Pelton turbine needle are identified. As seen from Figure $5 \& 6$ erosion is more in tip area. The authors explain the observed phenomenon based on relation between erosion and particle velocity $\left(\varepsilon_{\alpha} \alpha V_{p}{ }^{3}\right)$. The measurement of eroded needle profile of the same is also done. It can be seen about the near-tip erosion of the Pelton turbine needle. With decreasing cross-sectional flow area, the flow velocity increases (continuity equation) thus increasing the rate of erosion as flow approaches the needle tip. Near the tip, the force on the needle surface is low and jet flows under atmospheric pressure hence needle tip doesn't erode much. Furthermore, the authors highlight that needle erosion is less during the full opening of the needle and is much during part loading, mainly due to occurrence of cavitation during the latter case. By field investigation, the shape of eroded needle is studied and the eroded profile is developed (see Figure 6).

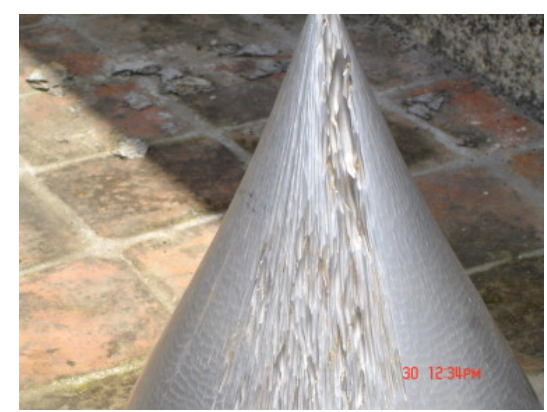

Figure 5: Needle damage due to erosion (Reproduced with permission from Bajracharya et al., 2008 [15])
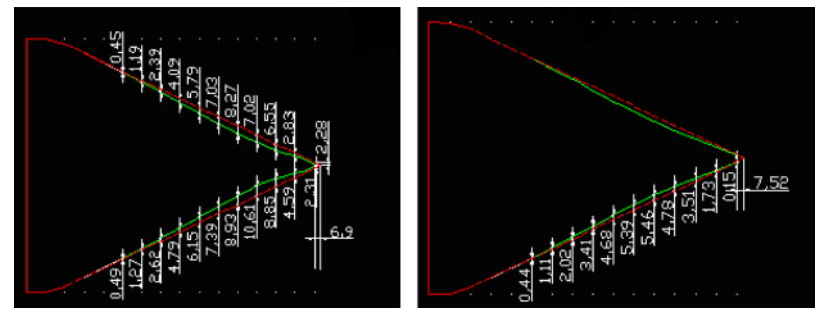

Figure 6: Eroded needle (Reproduced with permission from Bajracharya et al., 2008 [15])

In an experimental investigation about the jet dispersion, it has been concluded that poor jet quality is major cause of cavitation in bucket [32]. The phenomenon is validated by experimental observation in Fionnay Hydro Power Project (HPP). Application of CFD modeling to study the performance of different shape of nozzles (with needle geometry) on jet flow shows the capacity of commercial CFD modeling tools for modeling flow in Pelton turbine injector [33]. Numerical modeling of the flow in Pelton turbine injector using Lagrangian approach, smoothed particle hydrodynamics is done for the case of jet impingement on a flat plate and the flow pattern and pressure profile are then studied [34].

Neopane et al. [27] have reviewed the erosion in different types of hydro turbines. The authors have also reported about erosion seen in Pelton turbine parts. The bucket, needle and nozzle are identified as parts vulnerable to erosion. In [35,36] erosion in Pelton turbine needle is studied using CFD. As seen from the images published, there is a discrepancy between the results obtained and the actual erosion pattern. The authors have used commercial CFD code ANSYS Fluent for the study, and have reported the use of generic erosion model to predict erosion. The authors have used commercial CFD code ANSYS Fluent for the study and used the generic erosion model. The study shows the feasibility of using commercial CFD code ANSYS Fluent in prediction of wear in Pelton turbine needle by CFD based erosion modeling. Furthermore, the study establishes scope for further research in Pelton 
turbine needle thus opens door for further study and research.

In review about current state of the art in numerical modelling of Pelton turbine [37], the authors have reported about the numerical modelling of the flow in Pelton turbine injector. The authors highlight that the rotor jet interaction is more accurately modelled using ANSYS CFX while jet modelling is done with ANSYS Fluent. Benzon et al., $[38,39]$ have computationally studied flow in injector using commercial CFD code ANSYS Fluent. The authors have revealed about optimal combination of needle and nozzle angle. Several other authors [12,27, 28] also reveal the erosion in Pelton turbine injectors.

Experimental testing of the performance of coated needles (HVOF and plasma nitriding process) against the uncoated needle [40], reveals that coated needle has longer life than the original uncoated needle. The study performed by ANDRITZ hydro is the field setting research of HVOF coatings to combat hydro-abrasive erosion. The study reveals images of coated and uncoated needles in a two-nozzle Pelton turbine. As seen from the reported image the uncoated needle is severely eroded in tip area while the coated one is less eroded. Four times more life of the coated needle (steel coated with SXHTM 48 ) is then claimed by the reputed turbine manufacturers.

Numerical modelling of the hydro abrasive erosion in Pelton turbine injectors through numerical simulations [41] is done using commercial CFD code STAR CCM+ neglecting occurrence of cavitation in flow domain. The erosion pattern as predicted by Oka erosion model in the numerical simulation seems to agree with the previously published literature. Loss of efficiency due to needlenozzle eccentricity [42] shows that eccentricity is key factor of power loss for small Pelton turbines on partially open condition. As the geometry of the model, the distribution of sand particle size employed in these studies are different, there is scope for establishing the comparative study of experimental and numerical erosion occurring in Pelton turbine injector.

Table 1 summarizes the most relevant literatures. It can be seen that capacity assessment of different erosion models to predict erosion in Pelton turbine injector is least done. Comparison of results from experimental and computational modelling can give better understanding of the phenomenon and which among industrially accepted model can better predict the erosion phenomenon can be known. In addition, alteration of jet quality and loss of jet energy due to injector erosion needs to be studied.
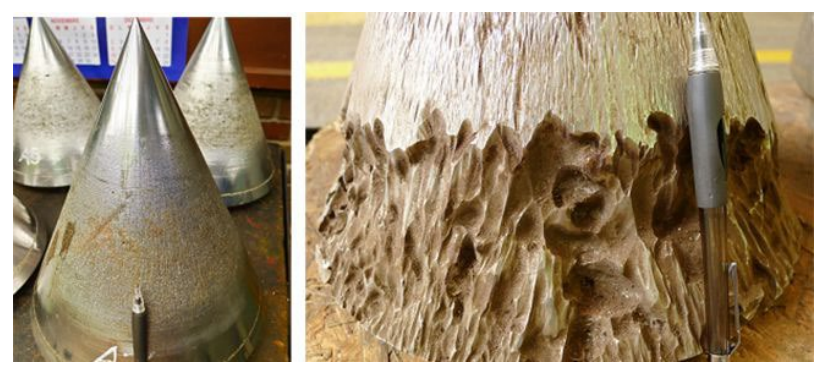

Figure 7: Erosion in the needle of Chivor HPP (Adapted from Morales et al. [28])
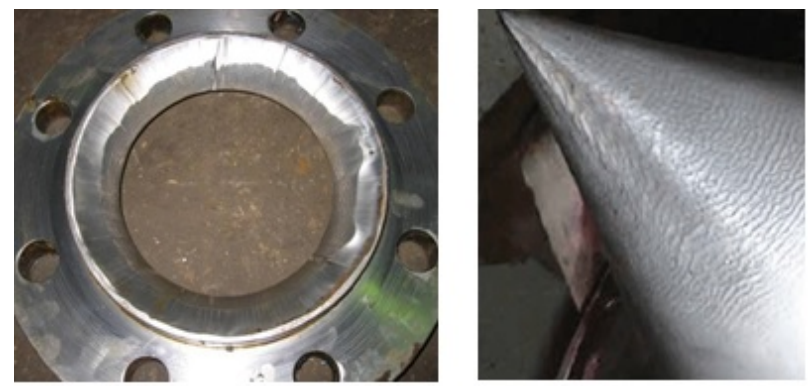

Figure 8: Erosion in Nozzle and Needle (On left, Erosion in nozzle ring of Andhi Khole HPP, Nepal and needle erosion in Khimti HPP, Nepal (Adapted from Neopane et al. [27])

\section{Discussion}

Engineering systems are designed to have long life and reliable performance. Occurrence of erosion in fluid flow systems is a challenging issue and many studies are being done to tackle this challenge and huge resources are being spent. Different researchers across the globe has attempted to quantitatively study the erosion phenomenon. It has been clearly understood from literature that prediction of commencement of erosion is a challenge and the proposed erosion models are case dependent i.e. a model which closely predicts erosion occurring in one case fails to predict for other case. Table 1 shows the summary of literature of study in Pelton turbine needle.

The coupling of CFD simulation and erosion models to predict erosion can general be understood as a three-step process.

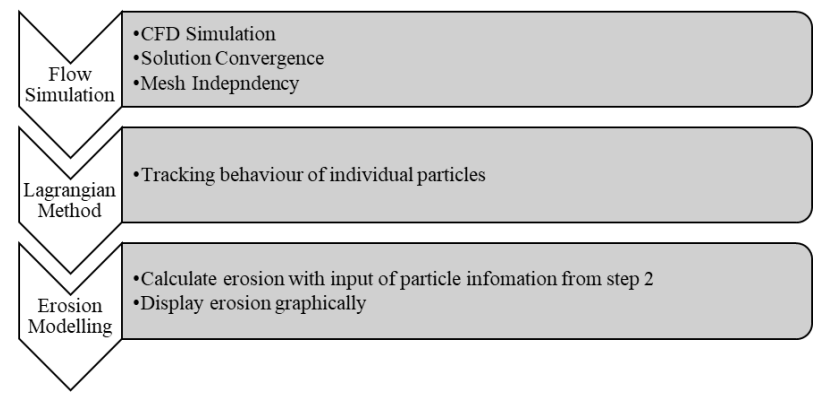

Figure 9: Methodology for CFD based erosion modelling 
Solid Particle Erosion Models and their Application to Predict Wear in Pelton Turbine Injector

Table 1: Summary of Published Literature

\section{SN Author(s) Year Approach Major Findings}

1. Nonoshita 1996 Computational The needle considerably affects the velocity distribution in the jet and the velocity et al. 1996 Computational distribution in the jet changes by the head

Staubli and For different needle position, the image of Pelton turbine jet is captured for the case of

2. Hauser 2004 Experimental moccasin power plant.

Variation of jet diameter with nozzle opening is studied.

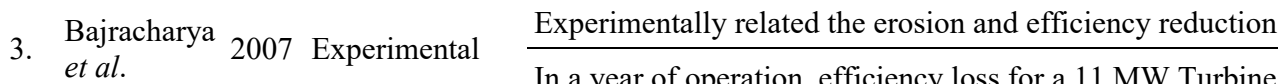

In a year of operation, efficiency loss for a $11 \mathrm{MW}$ Turbine was $1.21 \%$

Jet dispersion is described and reviewed

4. Peron et al. 2008 Experimental Poor jet quality is responsible for cavitation.

Influence of jet dispersion in Fionnay HPP is discussed

5. Gupta et al. 2009 Computational Keeping spear geometry same, the performance of different nozzle geometry is studied.

6. Papantonis 2009 Numerical Lagrangian approach, Smoothed Particle Hydrodynamics (SPH) is applied to model flow in

6. et al. 2009 Numerical Pelton turbine injector.

7. Neopane 2011 Review Erosion in different parts of Pelton turbine are studied. Needle seat, Needle and Bucket are

- et al. highlighted as parts most vulnerable to erosion

2014 Computational Feasibility of CFD modelling of erosion in Pelton turbine nozzle

8. Chongji 2015 Computational Used generic erosion modelling and it is seen that large particles cause more erosion et al.

2016 Computational

Three-dimensional numerical simulations of Jet flow and secondary flow phenomenon induced due to bends are highlighted.

Numerical modelling of Pelton turbine is summarized

9. Židonis and 2015 Review

Rotor and jet interaction are more accurately modelled with ANSYS CFX, Jet modelling is done with ANSYS Fluent

ANSYS Fluent is utilized for jet flow while CFX is employed for jet-bucket interaction.

10. Benzon 2015 Computational
et al.

Numerical modelling of Different curvature of needle is performed using ANSYS Fluent and ANSYS CFX.

Positive Curvature of spear geometry results in reduced losses.

Needle erosion is studied

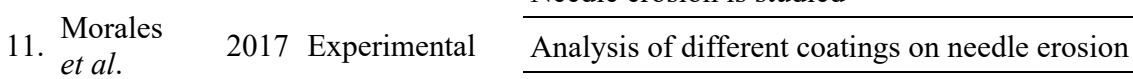

Coatings improve life of needle

Classification of erosion pattern that was seen in Pelton turbine buckets is done

12. Rai et al. 2017 Field Study

Sediment shape, size and concentration alters the erosion pattern.

More erosion is seen in monsoon season than in winter season

13. Sangal
et al.

Erosion behaviour and Erosion models generally applied for study of erosion in Francis turbine are summarized

14. Zhang 2018 Computational
et al.

Three-dimensional numerical simulation of Pelton turbine jet is performed using ANSYS CFX

Variation of efficiency with different combination of needle and nozzle angle

15. Jeon et al. 2018 Computational For different spear position, variation of head loss coefficient is studied.

Two erosion models are compared

16. Messa

2019 Computational

Erosion prediction is highly dependent on choice of erosion model

Realizable k-epsilon model is better choice

Computational

17. Jung et al. 2019 and Effect of jet spear needle eccentricity is studied

Experimental

Power loss is significant for jet eccentricity $>2 \%$ and is much significant for nozzle opening $<60 \%$ 
As summarized in Figure 9, the first step is flow simulation of the fluid flow domain which is again subdivided into three process namely, pre-processing (Domain modeling, Domain discretization and input the boundary condition), solution (Numerically solve the Navier-Stokes equation in the discretized domain) and post-processing (view results of numerical simulation and compare with that from experiments for model validation). It should be clearly understood that CFD simulations are Garbage-in, Garbage out studies. Hence, it is necessary for validation of the flow modeling which must be done by mesh independency test and importantly be verified using results from theoretical and experimental studies. The second step is introducing the Lagrangian method to track behavior of each particle to get information like particle velocity, particle impact angle. This information is then further processed to our selected erosion models which comprises the third step. The results are then obtained in graphical form either as erosion marked in surface of the target or plots.

The dedicated study to study about erosion in Pelton turbine needle started a decade ahead. Starting with experimental studies, present trend is to evaluate the erosion by CFD modeling. Though some models employed predicts the erosion pattern, the quantitative evaluation of the errors present by use of various models needs to be identified. In case of Pelton turbine needle, studies to quantify erosion occurring and techniques to minimize the erosion are reported. Area near to the tip are more prone to erosion however tip itself is free from erosion.

Experimental and Field studies have reported the erosion pattern seen in the needle after hours of operation in sediment laden flow. The erosion pattern obtained by using Oka erosion model predicts the erosion pattern more correctly in comparison to the DNV model. Finne erosion model is the first erosion model and is been improved for predicting erosion in Ductile materials. Mclaury erosion model is proposed for predicting erosion due to slurry flow. Recent studies to predict erosion in Pelton turbine needle by CFD modeling shows that with recent commercial CFD codes and CPU power, it is possible to model the case by CFD.

\section{Conclusion}

From above discussion, it can be concluded that:

- It would be recommended to compare erosion from Finnie, Tilly, McLaury, Oka and DNV models to discuss about errors in erosion prediction by these models in case of Pelton turbine needle as these models are mostly recognized models for predicting erosion. Furthermore, the experimental comparison of Oka and DNV model will be validation of findings published in [41].

- Experimentally, coatings are found to improve the life of Pelton turbine needle. Hence there is scope to compare erosion with coated and non-coated needle by CFD modeling to evaluate economics of coatings against the life and cost of coating.

- When the detailed numerical modeling is compared with experimental data, the factors causing discrepancy between the results may be identified.

- Eroded needle alters the jet quality thus will alter the efficiency of the turbine. Experimental study done can reveal the significance of the needle/nozzle erosion on efficiency of turbine.

\section{Acknowledgments}

The study was supported by Grant (Award No. FRG/74_75/Engg-4) from University Grants Commission, Bhaktapur, Nepal. The authors would like to thank Center for Energy Studies, Institute of Engineering, Mr. Janak Kumar Tharu, Mr. Sourav Dhungana and Mr. Anil Sapkota for their support in compiling this article.

\section{References}

[1] S. L. Sinha, S. K. Dewangan, and A. Sharma, “A review on particulate slurry erosive wear of industrial materials: In context with pipeline transportation of mineral-slurry," Part. Sci. Technol., vol. 35, no. 1, pp. 103-118, Jan. 2017.

[2] L. Poudel, B. Thapa, B. P. Shrestha, B. S. Thapa, K. P. Shrestha, and N. K. Shrestha, "Computational and experimental study of effects of sediment shape on erosion of hydraulic turbines," IOP Conf. Ser. Earth Environ. Sci., vol. 15 , no. 3, p. 032054 , Nov. 2012.

[3] B. Chhetry and K. Rana, "Effect of Sand Erosion on Turbine Components: A Case Study of Kali Gandaki 'A' Hydroelectric Project (144 MW), Nepal,” Hydro Nepal J. Water, Energy Environ., vol. 17, no. 0, p. 24, Aug. 2015.

[4] S. Sangal, M. K. Singhal, and R. P. Saini, "Hydro-abrasive erosion in hydro turbines: a review," Int. J. Green Energy, vol. 15, no. 4, pp. 232-253, Mar. 2018.

[5] D. R. Andrews, "An analysis of solid particle erosion mechanisms," J. Phys. D. Appl. Phys., vol. 14, no. 11, pp. 1979-1991, Nov. 1981.

[6] M. Parsi, K. Najmi, F. Najafifard, S. Hassani, B. S. McLaury, and S. A. Shirazi, "A comprehensive review of solid particle erosion modeling for oil and gas wells and pipelines applications," Journal of Natural Gas Science 
and Engineering, vol. 21. Elsevier, pp. 850-873, 01-Nov2014.

[7] OD Thapar, Modern Hydroelectric Engg Practice. Alternate Hydro Energy Center, Indian Institute of Technology Roorkee.

[8] S. L. Dixon and C. A. Hall, Fluid mechanics and thermodynamics of turbomachinery. ButterworthHeinemann/Elsevier, 2010.

[9] J. M. Throneberry, Y. Zhang, B. S. McLaury, S. A. Shirazi, and E. F. Rybicki, "Solid-Particle Erosion in Slug Flow," in SPE Annual Technical Conference and Exhibition, 2010.

[10] V. Javaheri, D. Porter, and V.-T. Kuokkala, "Slurry erosion of steel - Review of tests, mechanisms and materials," Wear, vol. 408-409, pp. 248-273, Aug. 2018.

[11] I. Finnie, "Erosion of surfaces by solid particles," Wear, vol. 3, no. 2, pp. 87-103, Mar. 1960.

[12] B. Thapa, "Sand Erosion in Hydraulic Machinery," Fakultet for ingeniørvitenskap og teknologi, 2004.

[13] P. A. Vesilind, "The Rosin-Rammler particle size distribution," Resour. Recover. Conserv., vol. 5, no. 3, pp. 275-277, Sep. 1980.

[14] H. P. Neopane and S. Sujakhu, "PARTICLE SIZE DISTRIBUTION AND MINERAL ANALYSIS OF SEDIMENTS IN NEPALESE HYDROPOWER PLANT: A CASE STUDY OF JHIMRUK HYDROPOWER PLANT," 2013.

[15] T. R. Bajracharya, B. Acharya, C. B. Joshi, R. P. Saini, and O. G. Dahlhaug, "Sand erosion of Pelton turbine nozzles and buckets: A case study of Chilime Hydropower Plant," Wear, vol. 264, no. 3-4, pp. 177-184, Feb. 2008.

[16] P. Raj Joshi, "Study of Suspended Sediment and Its Mineral Content Analysis with Impact on Hydropower Design: A Case Study of Rahughat Hydroelectric Project," J. Geol. Resour. Eng., vol. 2, pp. 82-86, 2017.

[17] J. H. Neilson and A. Gilchrist, "Erosion by a stream of solid particles," Wear, vol. 11, no. 2, pp. 111-122, Feb. 1968.

[18] G. P. Tilly, "A two stage mechanism of ductile erosion," Wear, vol. 23, no. 1, pp. 87-96, Jan. 1973.

[19] W. H. Jennings, W. J. Head, and C. R. Manning, “A mechanistic model for the prediction of ductile erosion," Wear, vol. 40, no. 1, pp. 93-112, Oct. 1976.

[20] G. Sundararajan, "A comprehensive model for the solid particle erosion of ductile materials," Wear, vol. 149, no. 1-2, pp. 111-127, Sep. 1991.

[21] B. S. McLaury, J. Wang, S. A. Shirazi, J. R. Shadley, and E. F. Rybicki, "Solid Particle Erosion in Long Radius Elbows and Straight Pipes," in SPE Annual Technical Conference and Exhibition, 1997.
[22] Y. I. Oka and T. Yoshida, "Practical estimation of erosion damage caused by solid particle impact: Part 2: Mechanical properties of materials directly associated with erosion damage," Wear, vol. 259, no. 1-6, pp. 102 109, Jul. 2005.

[23] Y. I. Oka, K. Okamura, and T. Yoshida, "Practical estimation of erosion damage caused by solid particle impact: Part 1: Effects of impact parameters on a predictive equation," Wear, vol. 259, no. 1-6, pp. 95-101, Jul. 2005.

[24] ANSYS Inc, "FLUENT 6.3 User's Guide - 22.5 Particle Erosion and Accretion Theory." [Online]. Available: https://www.sharcnet.ca/Software/Fluent6/html/ug/node81 8.htm. [Accessed: 25-Sep-2018].

[25] C. Duan and V. I. (Vladimir I. Karelin, Abrasive erosion \&amp; corrosion of hydraulic machinery, vol. 2. 2002.

[26] Eltvik Mette, "Sediment erosion in Francis turbines," Ph.D. thesis, no. June, 2013.

[27] H. P. Neopane, O. Gunnar Dahlhaug, and M. Cervantes, "Sediment Erosion in Hydraulic Turbines," Glob. J. Res. Eng. Mech. Mech. Eng., no. 6, pp. 17-26, 2011.

[28] A. M. Morales B, I. F. Pachón, J. Loboguerrero U, J. A. Medina, and J. A. Escobar G, "Development of a test rig to evaluate abrasive wear on Pelton turbine nozzles. A case study of Chivor Hydropower," Wear, vol. 372-373, pp. 208-215, Feb. 2017.

[29] T. Nonoshita, Y. Matsumoto, T. Kubota, and H. Ohashi, "Numerical Simulation of Jet in a Pelton Turbine," Hydraul. Mach. Cavitation, pp. 352-360, 1996.

[30] T. Staubli and H. P. Hauser, "Flow visualization - a diagnosis tool for pelton turbines," no. 1, pp. 1-9, 2004.

[31] Z. Zhang and M. Casey, "Experimental studies of the jet of a Pelton turbine," Proc. Inst. Mech. Eng. Part A J. Power Energy, vol. 221, no. 8, pp. 1181-1192, Jan. 2007.

[32] M. Peron, E. Parkinson, L. Geppert, and T. Staubli, "IMPORTANCE OF JET QUALITY ON PELTON EFFICIENCY AND CAVITATION," in IGHEM 2008 MILANO 3rd-6th September International Conference on Hydraulic Efficiency Measurements, 2008, no. September, pp. 1-9.

[33] V. Gupta, V. Prasad, and R. Khare, "Effect of Jet Shape on Flow and Torque Characteristics of Pelton Turbine Runner," J. Eng. Res. Appl.www.ijera.com, vol. 4, no. 1, pp. 318-323, 2014.

[34] D. E. Papantonis, J. S. Anagnostopoulos, and P. K. Koukouvinis, "Flow modelling in the injector of a Pelton turbine," 4th Int. SPHERIC Work., no. May 2009, pp. 1-8, 2009.

[35] Z. W. Chongji Zeng, Y.X. Xiao, Jianbo Zhang, SooHwang Ahn, "Numerical analysis of pelton turbine needle erosion characteristics," Paiguan Jixie Gongcheng 
Xuebao/Journal Drain. Irrig. Mach. Eng., vol. 33, no. 5, pp. 407-411, 2015.

[36] Z. Chongji, X. Yexiang, Z. Wei, Y. Yangyang, C. Lei, and W. Zhengwei, "Pelton turbine Needle erosion prediction based on 3D three- phase flow simulation," IOP Conf. Ser. Earth Environ. Sci., vol. 22, no. 5, p. 052019, Mar. 2014.

[37] A. Židonis and G. A. Aggidis, "State of the art in numerical modelling of Pelton turbines," Renew. Sustain. Energy Rev., vol. 45, pp. 135-144, May 2015.

[38] D. Benzon, A. Židonis, A. Panagiotopoulos, G. A. Aggidis, J. S. Anagnostopoulos, and D. E. Papantonis, "Impulse Turbine Injector Design Improvement Using Computational Fluid Dynamics," J. Fluids Eng., vol. 137, no. 4, p. 041106, Apr. 2015.

[39] D. Benzon, A. Židonis, A. Panagiotopoulos, G. A. Aggidis, J. S. Anagnostopoulos, and D. E. Papantonis, "Numerical Investigation of the Spear Valve Configuration on the Performance of Pelton and Turgo Turbine Injectors and Runners," J. Fluids Eng., vol. 137, no. 11, p. 111201, 2015.

[40] D.A.Karandikar, "HVOF Coatings to combat hydro abrasive erosion International Conference On Hydropower Sustainable Development Dehradun 6 th," 2015.

[41] G. V. Messa, S. Mandelli, and S. Malavasi, "Hydroabrasive erosion in Pelton turbine injectors: A numerical study," Renew. Energy, vol. 130, pp. 474-488, Jan. 2019.

[42] I. H. Jung, Y. S. Kim, D. H. Shin, J. T. Chung, and Y. Shin, "Influence of spear needle eccentricity on jet quality in micro Pelton turbine for power generation," Energy, vol. 175, pp. 58-65, May 2019.

[43] T. R. Bajracharya, "Efficiency Deterioration in Pelton Turbines due to Sand-Particle-Led Bucket Erosion," Tribhuvan University, 2007.

[44] A. K. Rai, A. Kumar, and T. Staubli, "Hydro-abrasive erosion in Pelton buckets: Classification and field study," Wear, vol. 392-393, pp. 8-20, Dec. 2017.

[45] J. Zhang et al., "Optimal design of a pelton turbine nozzle via 3D numerical simulation," IOP Conf. Ser. Earth Environ. Sci., vol. 163, no. 1, 2018.

[46] H. Jeon, J. H. Park, Y. Shin, and M. Choi, "Friction loss and energy recovery of a Pelton turbine for different spear positions," Renew. Energy, vol. 123, pp. 273-280, Aug. 2018. 